\author{
Jean-Christophe Lucet \\ Despoina Koulenti \\ Jean-Ralph Zahar
}

\section{Persistence of colonisation with MDRO following discharge from the ICU}

Received: 24 February 2014

Accepted: 26 February 2014

Published online: 8 March 2014

(C) Springer-Verlag Berlin Heidelberg and ESICM 2014

\section{J.-C. Lucet ( $\square)$}

Infection Control Unit, Bichat-Claude Bernard Hospital, Assistance publique-Hôpitaux de Paris (AP-HP), Paris, France e-mail: jean-christophe.lucet@bch.aphp.fr

\section{J.-C. Lucet}

IAME, Unité mixte de recherche (UMR) 1137, Institut National de la Santé et de la Recherche Médicale (INSERM), 75018 Paris, France

\section{J.-C. Lucet}

University of Paris Diderot, Sorbonne Paris Cité, 75018 Paris, France

\section{Koulenti}

Critical Care Department, Attikon University Hospital,

Athens, Greece

\section{Koulenti}

Burns, Trauma and Critical Care Research Centre,

The University of Queensland, Brisbane, Australia

\section{J.-R. Zahar}

Infection Control Unit, Angers University Hospital, Université d'Angers, Angers, France

Multidrug resistant organisms (MDROs) represent not only a major threat to public health but also place a significant burden on patients and healthcare systems. The incidence of MDROs is increasing rapidly worldwide, and several MDROs cause infections for which virtually no effective antibiotic is currently available. When a patient is colonised with a MDRO, it is important to determine the duration of colonisation and when it is safe to discontinue contact precautions. As carriers may reintroduce the MDRO into healthcare facilities, with the risk of subsequent spread of the infection, identification of the risk factors associated with prolonged carriage is critical.

Identifying persistent carriers at readmission has become an integral part of programmes designed to control the spread of MDROs in healthcare facilities. Many studies have focused on the use of early medical alert systems at readmission with the aim of establish the duration of MDRO carriage. In a study published in this issue of Intensive Care Medicine, Haverkate and colleagues assessed the duration of MDRO carriage using data from the MOSAR intensive care unit (ICU) trial that included 14,390 patients from 13 ICUs in eight European countries [1]. The aim of the MOSAR ICU trial was to assess the impact of different strategies to control the spread of MDRO, while the goal of this ancillary study was to determine the duration of colonisation with various MDROs, namely methicillin-resistant Staphylococcus aureus (MRSA), highly resistant enterobacteriaceae (HRE), most of which are extended-spectrum beta-lactamase-producing Enterobacteriaceae (ESBLPE) and vancomycin-resistant enterococci (VRE).

The patients included in the study of Haverkate et al. [1] had been colonised with a MDRO during a previous stay in the ICU and later readmitted to the ICU and screened. When all MDROs were considered together, the median duration of carriage was 4.8 months; in comparison, the median duration of carriage of MRSA, HRE and VRE when considered separately was $0.4,1.4$ and 1.5 months, respectively. The major strengths of this study are its multicentre design, the assessment of carriage of several MDROs in the same patient population and the statistical analysis that accurately accounts for censoring. Surprisingly, the median duration reported by 
these authors for each category of MDRO is shorter than those reported in earlier studies (Table 1). The authors substantiated their results by performing both a sensitivity analysis which showed that their results remained stable under different hypotheses and different analyses to calculate the survival function.

Several factors could explain the differences between the results of Haverkate et al. [1] and those reported by authors of other studies in the field. As mentioned, the study of Haverkate and colleagues was derived from the MOSAR ICU trial, which was not designed to assess MDRO clearance. The authors also acknowledged several limitations to their study, including a lower sensitivity to detect persistent carriage because of: (1) screening samples without enrichment broth, (2) using perirectal swabs rather that rectal swabs for detecting VRE and HRE and (3) freezing and storage of the swabs before culture during one study phase. In addition, patients were considered to be free of MDRO carriage if the results of two successive screenings were negative, whereas most guidelines recommend three negative samplings due to possible intermittent carriage
$[2,3]$. While all of these factors could account for a false negative screening at readmission in the study of Haverkate and colleagues, they are unlikely to account for the important difference in MDRO clearance compared to data reported previously.

The short duration of MDRO carriage reported by Haverkate et al. [1] is at odds with that expected in this patient population. Indeed, the study population was likely to be at high risk of persistent carriage as the included patients were first discharged from the ICU and then readmitted to the ICU at a later date. Unfortunately, factors previously reported to be associated with persistent carriage, such as the presence of invasive devices, antimicrobial exposure and stay in a downstream unit after ICU discharge, were not recorded by these authors.

It is important to emphasise that the survival curves (see Figure 2 of Haverkate et al. [1]) depict that the clearance of MDROs may have two slopes: an initially short 1- to 2-month period with rapid MDRO clearance in half of the carriers, followed by a plateau of 1 year with persistent carriage of HRE and MRSA in about $40 \%$ of

Table 1 Description of studies that have assessed the duration of carriage in various multidrug resistant organisms

\begin{tabular}{|c|c|c|c|}
\hline Studies on multidrug resistant organisms & Patients $(n)$ & $\begin{array}{l}\text { Duration of carriage, } \\
\text { months (median) }\end{array}$ & $\begin{array}{l}\text { Factors associated } \\
\text { with prolonged carriage }\end{array}$ \\
\hline \multicolumn{4}{|c|}{ Methicillin-resistant Staphylococcus aureus (MRSA) } \\
\hline Scanvic et al. [6] & 78 & 8.5 & $\begin{array}{l}\text { Skin lesions } \\
\text { LTCF }\end{array}$ \\
\hline Marshall et al. [7] & 116 & 7.4 & $\begin{array}{l}\text { Skin lesions } \\
\text { Antibiotic treatment } \\
\text { Indwelling devices } \\
\text { Immunosuppressive therapy } \\
\text { Haemodialysis } \\
\text { Eradication treatment }\end{array}$ \\
\hline Robicsek et al. [4] & 824 & 1 & $\begin{array}{l}\text { ICU } \\
\text { Pressure ulcer }\end{array}$ \\
\hline Mattner et al. [3] & 403 & 18.3 & Multiple sites of colonisation \\
\hline Larsson et al. [8] & 535 & 5.9 & $\begin{array}{l}\text { Household contact with MRSA } \\
\text { Young age } \\
\text { Spa type t002 } \\
\text { Multiple sites of colonisation } \\
\text { Eradication treatment (protective) }\end{array}$ \\
\hline Haverkate et al. [1] & 48 & 0.4 & ND \\
\hline \multicolumn{4}{|c|}{ Highly resistant enterobacteriacae (HRE) (ESBL) } \\
\hline Apisarnthanarak et al. [9] & 24 & 3.4 & Antibiotic treatment \\
\hline Zahar et al. [10] & 62 & 4.4 & Rehabilitation unit \\
\hline Birgand et al. [11] & 448 & 6.6 & Colonisation only \\
\hline Titelman et al. [12] & 61 & $\sim 8$ & $\begin{array}{l}\text { Phylogroup B2 } \\
\text { CTX-M9 }\end{array}$ \\
\hline Haverkate et al. [1] & 101 & 1.4 & ND \\
\hline \multicolumn{4}{|c|}{ Carbapenemase-producing enterobacteriacae (CPE) } \\
\hline Feldman et al. [13] & 125 & ND & $\begin{array}{l}\text { Invasive device } \\
\text { Low functional status } \\
\text { LTCF }\end{array}$ \\
\hline \multicolumn{4}{|l|}{ Vancomycin-resistant enterococci (VRE) } \\
\hline Mascini et al [14] & 20 & $>6$ & Carriage of the outbreak isolate \\
\hline Byers et al [2] & 116 & ND & Antibiotic treatment \\
\hline Haverkate et al. [1] & 19 & 1.5 & ND \\
\hline
\end{tabular}

ESBLPE Extended-spectrum betalactamase-producing enterobacteriacae, $I C U$ intensive care unit, $N D$ not determined, $L T C F$ long-term care facilities 
the initial population. The same pattern has been observed in other published studies [4]. The phenomenon of rapid clearance may correspond to a specific population without risk factors for persistence, whereas the persistence could correspond to patients with risk factors associated with persistent carriage.

It is unclear why the results of Haverkate et al. [1] differ from those of previous studies. However, the median duration of carriage in their study was similar for the three MDROs under surveillance, which is in accordance with published data. Apart from chronic skin lesions that are specifically associated with prolonged MRSA carriage, other risk factors for persistent carriage are similar for these three MDROs, i.e. stay in a long-term care facility or rehabilitation unit, use of antimicrobials and invasive devices and debilitated state of patient (Table 1). Even using these risk factors, a score of colonisation persistence with high negative predictive value is still needed in order to limit active surveillance to a subset of at-risk patients at hospital and ICU admission.

In conclusion, the high percentage of persistent carriage of MDROs up to 1 year after discharge from the ICU highlights the ability of MDROs to persist in susceptible patients and to form a reservoir for dissemination at readmission [5]. In line with results reported previously, the findings of Haverkate et al. [1] support the use of hospital information system-based automatic alerts for preventing the transmission of MDROs.

\section{References}

1. Haverkate MR, Derde LPG, BrunBuisson C, Bonten MJM, Bootsma MCJ (2014) Duration of colonization with antimicrobial-resistant bacteria after ICU discharge. Intensive Care Med. doi:10.1007/s00134-014-3225-8

2. Byers KE, Anglim AM, Anneski CJ, Farr BM (2002) Duration of colonization with vancomycin-resistant Enterococcus. Infect Control Hosp Epidemiol 23:207-211

3. Mattner F, Biertz F, Ziesing S, Gastmeier P, Chaberny IF (2010) Longterm persistence of MRSA in readmitted patients. Infection 38:363-371

4. Robicsek A, Beaumont JL, Peterson LR (2009) Duration of colonization with methicillin-resistant Staphylococcus aureus. Clin Infect Dis 48:910-913

5. Jones M, Ying J, Huttner B et al (2014) Relationships between the importation, transmission, and nosocomial infections of methicillin-resistant Staphylococcus aureus: an observational study of 112 Veterans Affairs Medical Centers. Clin Infect Dis 58:32-39

6. Scanvic A, Denic L, Gaillon S, Giry P, Andremont A, Lucet JC (2001) Duration of colonization by methicillinresistant Staphylococcus aureus after hospital discharge and risk factors for prolonged carriage. Clin Infect Dis 32:1393-1398
7. Marschall J, Muhlemann K (2006) Duration of methicillin-resistant Staphylococcus aureus carriage, according to risk factors for acquisition. Infect Control Hosp Epidemiol 27:1206-1212

8. Larsson AK, Gustafsson E, Nilsson AC, Odenholt I, Ringberg H, Melander E (2011) Duration of methicillin-resistant Staphylococcus aureus colonization after diagnosis: a four-year experience from southern Sweden. Scand J Infect Dis 43:456-462

9. Apisarnthanarak A, Bailey TC, Fraser VJ (2008) Duration of stool colonization in patients infected with extended-spectrum beta-lactamaseproducing Escherichia coli and Klebsiella pneumoniae. Clin Infect Dis 46:1322-1323

10. Zahar JR, Lanternier F, Mechai $F$ et al (2010) Duration of colonisation by Enterobacteriaceae producing extended-spectrum beta-lactamase and risk factors for persistent faecal carriage. J Hosp Infect 75:76-78

11. Birgand G, Armand-Lefevre L, Lolom I, Ruppe E, Andremont A, Lucet JC (2012) Duration of colonization by extended-spectrum beta-lactamaseproducing Enterobacteriaceae after hospital discharge. Am J Infect Control 41:443-447
12. Titelman E, Hasan CM, Iversen A, et al (2014) Fecal carriage of extendedspectrum beta-lactamase-producing Enterobacteriaceae is common twelve months after infection and is related to strain factors. Clin Microbiol Infect. doi:10.1111/1469-0691.12559

13. Feldman N, Adler A, Molshatzki N et al (2013) Gastrointestinal colonization by KPC-producing Klebsiella pneumoniae following hospital discharge: duration of carriage and risk factors for persistent carriage. Clin Microbiol Infect 19:E190-E196

14. Mascini EM, Jalink KP, KampHopmans TE et al (2003) Acquisition and duration of vancomycin-resistant enterococcal carriage in relation to strain type. J Clin Microbiol 41:5377-5383 